Gnbalta:Bergeidnié.

\title{
Erfte 2btheilung.
}

(Beididtlide entfebungunb Entwidelungbeg Strei= teb über bie $2 b_{g} a b e$ oon $x_{r}$ neimiteln an bie Aranten burd bie Xerzte.

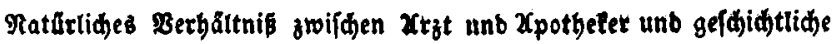

Beftaltung beffelben vor einer Befebgebung bartber.

Gefeggebung.

1. Periobe. Bon ben exften belannten Gefegen bis gu ben legten seidggejegen . . . . . . . . 5

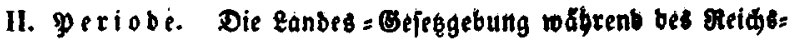
verbanbes. +,,,,++++

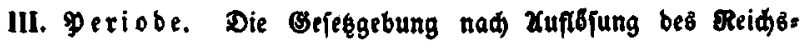
verbander. . . . . . . .

3 weite $2 b$ theilung.

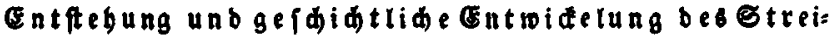
tes in bem exobyerzogthum geffen.

Xubbreitung bes bomöopatbif verfube. . . . . . . . . . . . . . . . .

Gelangung bes Gtreites an bie zanbfänbe unb 23 illfäbrigteit bes

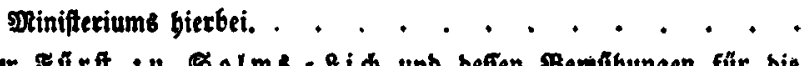

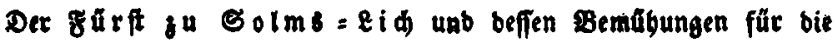
Xufredtbaltung bes neuen Geitberfabrens. Die Berbanblungen in ber zmeiten Rammer ber Eanbftănbe . . 33 Die Berbanbtungen in ber erften Rammer. . . . . . 34 Die Xufnabme bet Entjoheibung ber Lanbfänbe von Seiten bet Stantsergiecung. . . . . . . , . . . . . , 
Dritte $\mathcal{A b t h e i l u n g .}$

grăfung ber \& rünbe für und gegen ba G Selbft bi हpen= firen hemöopatbifder $\mathfrak{u}_{e} \mathfrak{r}_{\mathrm{z}}$ te.

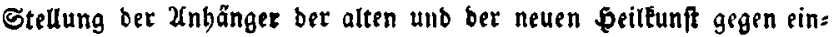
anter:

A. (S) rünoe gegen bas Selbfto ispeniten.

1. Privilegien Der Upothefer.

II. SBeftebende Befeggebung. . . . . . . . . . . . . 53

III. Nothmentigfeit bcjonberer Berbote ber Staatzoerwaltung. . 56

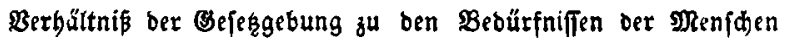
überhaupt und 2lufgabe der spolizeigejeģgebung . . . , 57

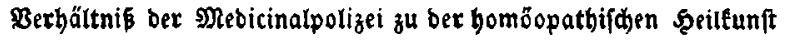
uno einem Dizpenfirverbot für bie 2lerzte. . . . . . . . . 61

1) wegen bes \$Bobls ber patienten. . . . . . . . 62

2) wegen Rotbwenbigkeit einer (5ontrole gegen bie Xirzte. 65

3) wegen Erafaltung ber Upotheten. . . . . . . 73

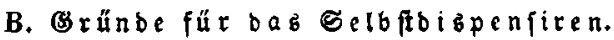

1. Nothwendigteit bes Selbftoibpenfirens gur Erbaltung und Ent= widelung ber \$omöopatbie. . . . . . . . . . . 7 T

II. Semeinidaftliches Sntereffe der \$atienten und bes Staats . 81

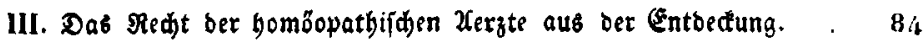

$\mathfrak{B}$ icrte $2 b$ theilung.

eeifungen ber tomöopatbie unb Erwartungen oon

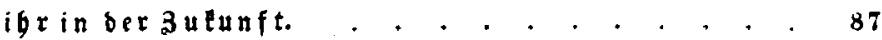

ureunben.

A. Borftellung an bie Eandftänbe. . . . . . . . . . 98

B. Xus\{dußberid)t ber zroeiten Rammer. . . . . . . . . 105

C. Rebe bes Zlbg. $\mathbb{B}$ olff. . . . . . . . . . . . . . 121

D. Dibfuffion in ber zweiten §ammer. . . . . . . . . 139

E. Xusfdupberidt ber erften Rammer. . . . . . . . . 158

F. Dibeuffion in ber exften fammer. . . . . . . . . 168

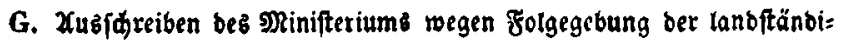
fhen Zuntrăge. . . . . . . . . . . . . . . . 17! 